\title{
SHORT COMMUNICATION Modelling of Nutrient Gradients in a Bacterial Colony
}

\author{
By STEVEN P. FRALEIGH AND HENRY R. BUNGAY* \\ Rensselaer Polytechnic Institute, Troy, NY 12180, USA
}

(Received 4 March 1986)

\begin{abstract}
Oxygen and substrate gradients were simulated with a finite-volume method for a variety of bacterial colony sizes and substrate concentrations. A spherical segment geometry and a Monod relationship for simultaneous substrate and $\mathrm{O}_{2}$ consumption were assumed. The results agreed well with previous theoretical and experimental estimates for gradients in microbial colonies.
\end{abstract}

\section{INTRODUCTION}

A microbial colony arises from one or a few cells. Modelling of this evolving ecosystem is complicated because of ranges in metabolic states and morphology, and colony growth depends on diffusion rates of essential nutrients.

Pirt (1967) considered physical and chemical factors affecting colony growth on solid media. Using data from macroscopic observations, his theory estimated that $\mathrm{O}_{2}$ tension would be low at a depth of about $40 \mu \mathrm{m}$ in an active colony. Wimpenny \& Lewis (1977) measured the actual $\mathrm{O}_{2}$ consumption rate for bacterial colonies via respirometry. Treating these data with the assumption of a spherical segment, the calculated thickness of the aerobic 'shell', or penetration depth of $\mathrm{O}_{2}$, was $30-40 \mu \mathrm{m}$, depending on the bacterial species. Aerobic activity diminished as the colony aged. Wimpenny (1979) showed that with Escherichia coli, Staphylococcus albus and Bacillus cereus the spherical segment is a good approximation of colony shape.

Wimpenny \& Coombs (1983) measured $\mathrm{O}_{2}$ gradients in $B$. cereus colonies growing on agar and found contours similar to those observed in Pseudomonas ovalis colonies by Bungay et al. (1983). In general, steep $\mathrm{O}_{2}$ gradients occurred near the colony surfaces, unless there was too little organic nutrient to create a strong demand. The extent of $\mathrm{O}_{2}$ penetration varied with substrate concentration. The interior of colonies grown on dilute media showed abundant dissolved $\mathrm{O}_{2}$, while those grown with supplemental glucose had significant regions of low $\mathrm{O}_{2}$ tension (Bungay et al., 1983). In this study we have used computer simulations to facilitate the analysis of $\mathrm{O}_{2}$ contours for respiring organisms and to aid the design of experiments.

\section{METHODS}

A typical microbial colony is several millimetres in diameter but nutrients such as $\mathrm{O}_{2}$ and glucose can diffuse through it in a few minutes. Based on relaxation times (e.g. Roels, 1983), a pseudo-steady state exists for nutrient gradients within the colony. The use of an unstructured kinetic model for nutrient uptake is appropriate in a computer simulation of discrete colony states.

The classic model of Monod (1942) is reliable for a single limiting nutrient; however, a colony system has two counterdiffusing limiting nutrients (substrate and $\mathrm{O}_{2}$ ). Many biokinetic studies use a double Monod form (Bader, 1978), but this model has no experimental validation and is inconsistent when both nutrients are in short supply. In our simulation, uptake rates at a location within the colony were found from local determinations of the most limiting nutrient. This allowed selection of the lowest rate from two separate Monod expressions. A yield coefficient set the uptake rate of the excess species. Table 1 lists values for the parameters used in the simulation. These were averaged from various literature sources (Haas, 1981; Bungay et al., 1969; Wimpenny, 1979). Determination of local kinetic parameters within colonies has not yet been reported, but spatial variation is likely. 
Table 1. Kinetic parameters and nutrient uptake

Parameter

Specific colony growth rate, $\mu_{\mathrm{m}}$ Biomass yield on substrate, $Y_{\mathrm{s}}$ Biomass yield on oxygen, $Y_{\mathrm{O}_{2}}$ Dry cell density, $\rho_{\mathrm{x}}$ Monod coefficient for substrate, $K_{\mathrm{s}}$ Monod coefficient for $\mathrm{O}_{2}, \mathrm{~K}_{\mathrm{O}_{2}}$ Effective diffusivity of substrate, $D_{\mathrm{s}}$ Effective diffusivity of $\mathrm{O}_{2}, D_{\mathrm{O}_{2}}$
Value

$0 \cdot 15 \mathrm{~h}^{-1}$

$0.5 \mathrm{~g}$ (g substrate) $)^{-1}$

$1.5 \mathrm{~g}^{\left(\mathrm{g} \mathrm{O}_{2}\right)^{-1}}$

$1.1 \mathrm{~g} \mathrm{ml}^{-1}$

$4 \times 10^{-6} \mathrm{~g} \mathrm{ml}^{-1}$

$4 \times 10^{-6} \mathrm{~g} \mathrm{ml}^{-1}$

$5 \times 10^{-7} \mathrm{~cm}^{2} \mathrm{~s}^{-1}$

$2 \times 10^{-6} \mathrm{~cm}^{2} \mathrm{~s}^{-1}$

As a first approximation, we assumed that the parameters in Table 1 do not change with position in the colony.

A well-defined system is important for the early stages of modelling. A major simplification was to define our system as a colony growing on a membrane over a well-mixed liquid medium so that the glucose concentration could be assumed constant at the base of the colony. Glucose diffuses up into the colony while $\mathrm{O}_{2}$ diffuses in through its exposed surface. Diffusion of $\mathrm{O}_{2}$ through the membrane was ignored in our simulation.

The numerical algorithm using a finite-volume method derived from the calculus of finite differences was advocated by Patankar (1980) on the grounds of simple physical interpretation. We modelled a colony as a segment of a spherical volume characterized by a certain height and radius. A subroutine connected our procedures to a packaged program available at Rensselaer Polytechnic Institute (RPI) for finite-volume analysis. The subroutine used the colony dimensions to calculate a differencing scheme in spherical coordinates, and it provided boundary conditions, the kinetic model, and the parameters in Table 1. All calculations were made on RPI's IBM $3081 \mathrm{D}$ mainframe computer. Details of the finite-volume subroutine in FORTRAN can be obtained from the authors.

\section{RESULTS}

Simulations were done with several combinations of colony size and external substrate concentration. Convergence of the numerical routines was rapid. Fig. 1 shows a series of simulated dissolved $\mathrm{O}_{2}$ profiles for a colony $110 \mu \mathrm{m}$ high and $5 \mathrm{~mm}$ radius. The varied parameter was external substrate (glucose) concentration $\left(50,500\right.$ and $\left.5000 \mathrm{mg} \mathrm{l}^{-1}\right)$, i.e. a range from limiting to excess supply at the colony surface. The contours for substrate are shown in Fig. 2. $\mathrm{O}_{2}$ was abundant where substrate was scarce, and became depleted (with steep gradients) where it was plentiful.

\section{DISCUSSION}

The contours in Fig. 1 are similar to contours from microelectrode studies. As external substrate concentration increases, there is a transition from a predominantly aerobic environment to one with significant anoxic regions. The penetration depth of $\mathrm{O}_{2}$ in the presence of excess substrate (Fig. 1c) was $30-40 \mu \mathrm{m}$, which agrees with previous findings (Pirt, 1967; Wimpenny \& Lewis, 1977). Simulations with smaller colonies showed an equivalent penetration depth (data not shown), hence smaller colonies have a larger proportion of aerobic activity. Increasingly anoxic environments in larger colonies probably contribute to toxic metabolite accumulation and eventual cessation of growth.

At present there are no experimental data to compare with the results shown in Fig. 2. Glucose microelectrodes have been constructed, but there are problems with stability and response time. Improved glucose sensors will reveal much more about colony growth.

Simulation of nutrient gradients is a first step in the development of a detailed colony growth model. Extending gradient analysis to the region of solid substrate below a colony is an important aim, but this requires a more elaborate numerical procedure that works with complicated geometry. We have had limited preliminary success with a finite-element implementation. Other aims are elucidation of kinetic and morphological parameters for colony systems. Factors that must be considered include spatial variation, product inhibition and the effects of age distribution. Computer simulations can have great value in organizing these experimental data and in exposing areas where further research is needed.

We thank Shailesh Agarwal for important contributions in the development of the finite-volume simulation. 


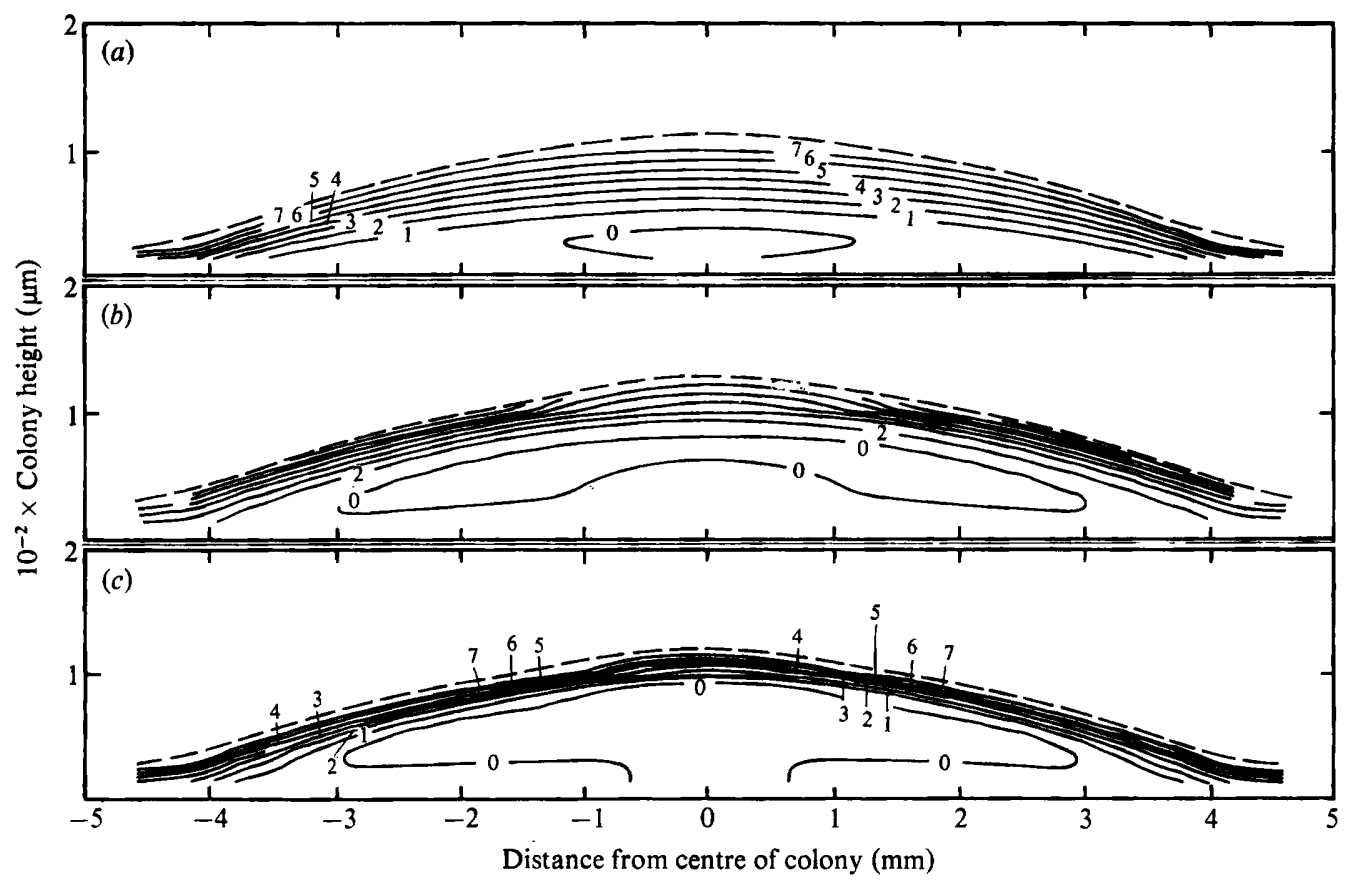

Fig. 1. Simulated $\mathrm{O}_{2}$ profiles for colonies of identical siże exposed to a range of glucose concentrations: (a) $50 \mathrm{mg} \mathrm{l}^{-1}$; (b) $500 \mathrm{mg} \mathrm{l}^{-1}$; (c) $5 \mathrm{~g} \mathrm{l}^{-1}$. The solubility of $\mathrm{O}_{2}$ was assumed to be $8.0 \mathrm{mg} \mathrm{l}^{-1}$. Isopleth values are $\mathrm{mg} \mathrm{l}^{-1}$.

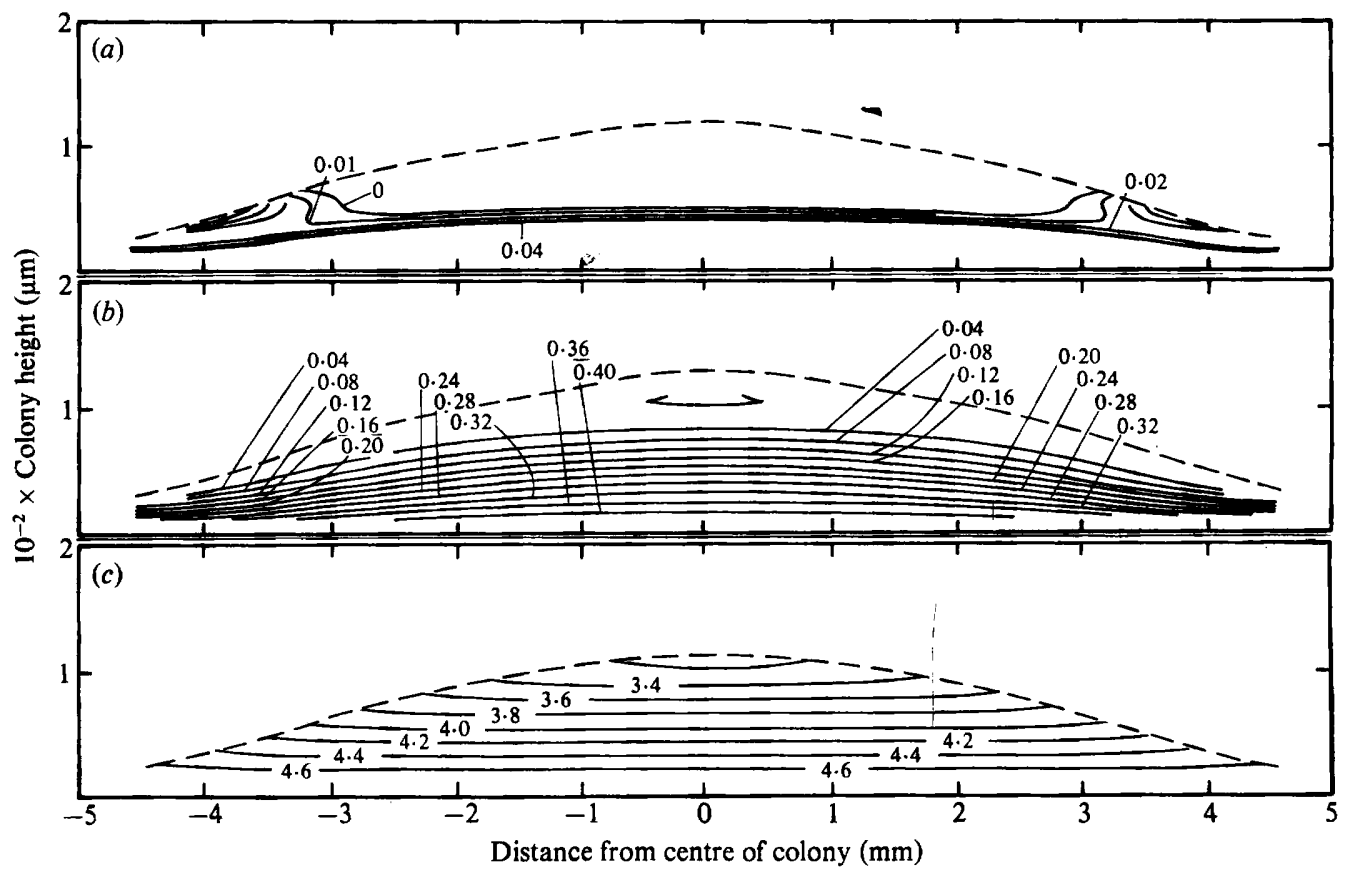

Fig. 2. Simulated glucose profiles for colonies of identical size exposed to a range of glucose concentrations: (a) $50 \mathrm{mg} \mathrm{l}^{-1} ;(b) 500 \mathrm{mg} \mathrm{l}^{-1} ;(c) 5 \mathrm{~g} \mathrm{l}^{-1}$. Isopleth values are $\mathrm{g} \mathrm{l}^{-1}$. 


\section{REFERENCES}

BADER, F. G. (1978). Analysis of substrate limited growth. Biotechnology and Bioengineering 20, 183202.

Bungay, H. R., Whalen, W. J. \& Sanders, W. M. (1969). Microprobe technique for determining diffusivities and respiration in microbial slime systems. Biotechnology and Bioengineering 11, 765772.

Bungay, H. R., Pettit, P. M. \& Drislane, A. M. (1983). Dissolved oxygen contours in Pseudomonas ovalis colonies. In American Chemical Society Symposium Series, vol. 207, pp. 395-402. Edited by H. Blanch, E. T. Papoutsakís \& G. Stephanopoulos. Washington, DC: American Chemical Society.

HaAs, C. N. (1981). Biological process diffusional limitations. Journal of the Environmental Engineering Division (American Society of Civil Engineers) 107, EE1, 269-273.
Monod, J. (1942). Recherches sur la Croissance des Cultures Bacteriennes. Paris: Hermann.

Patankar, S. V. (1980). Numerical Heat Transfer and Fluid Flow. New York: McGraw-Hill.

PIRT, S. J. (1967). A kinetic study of the mode of growth of surface colonies of bacteria and fungi. Journal of General Microbiology 47, 181-197.

RoEls, J. A. (1983). Kinetics and Energetics in Biotechnology. New York: Elsevier Biomedical Press.

WIMPENNY, J. W. T. (1979). The growth and form of bacterial colonies. Journal of General Microbiology 114, 483-486.

WIMPENNY, J. W. T. \& CoOMBs, J. P. (1983). Penetration of oxygen into bacterial colonies. Journal of General Microbiology 129, 1239-1242.

WIMPENNY, J. W. T. \& LeWIS, M. W. A. (1977). The growth and respiration of bacterial colonies. Journal of General Microbiology 103, 9-18. 